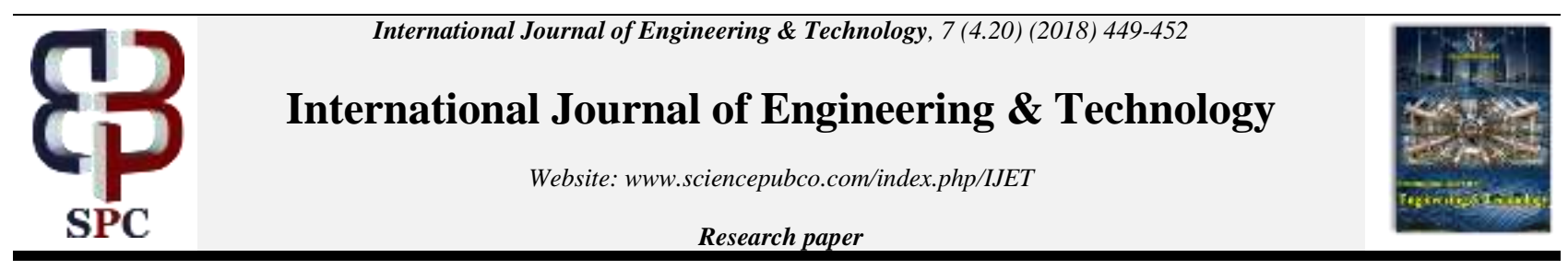

\title{
Possibility of Using Concrete Reinforced by Carbon Fibre in Construction
}

\author{
Nada Mahdi Fawzi Aljalawi ${ }^{*}$, Haider M.K. Al-Jelawy ${ }^{2}$ \\ ${ }^{1}$ University of Baghdad, civil engineering department \\ ${ }^{2}$ Uruk University \\ * Corresponding author E-mail: naljalawi@yahoo.com
}

\begin{abstract}
This work focuses on studying the mechanical characteristics of carbon fibre reinforced concrete, containing a different percentage of fibre. This work was carried out using several tests. These tests were hardened density, compressive strength, flexural strength . Tests were performed for specimens at ages of $(7,28,60)$ days. The test results indicated that the inclusion of fibre in the reference concrete mixes did not affect the compressive strength significantly, while the flexural strength was improved. Test results indicated that the flexural strength of $(0.75 \%)$ carbon fibre concrete specimens are twice that of the reference specimens in age of 28 days . The percentage of increasing the flexural strength for carbon mixes containing fibre by volume fraction of $(0.5 \%, 0.75 \%)$ were $(23 \%, 27 \%)$ respectively at age of 28 days.
\end{abstract}

Keywords: carbon fiber; compressive strength; flexural strength; reference specimens; density.

\section{Introduction}

Concrete is a composite material made from a filler which represented by the coarse granular material firmed in matrix which represented by the cementitious materials (the binder). The binder will fill the spaces between the filler particles and bond them together. However, it is a weak material having low rigidity and low strain ability that effect its tensile strength. For this purpose, fibre reinforced concrete(FRC)was created. Fibres help with enhancing is better ductile strength, flexural strength, toughness furthermore effect the concrete quality positively $[\mathbf{1 , 2 , 3}$.

This study focuses on the effect of carbon fibre on the properties of concrete. Moreover, carbon fibres have low density, particularly compared with steel fibre. Their strength-to density proportion is the highest amongst those most elevated fibres types. Carbon fibres have a higher quality compared to metallic fibres. This motivation was behind their utilization to produce composite materials with good properties such as polymeric composites. [4].

\subsection{Concrete Reinforced by Carbon Fibre}

Carbon fiber concrete framework composites are auxiliary materials that are picking up in significance quickly because of the abatement in carbon fiber cost and the expanding request of unrivaled basic and practical properties. These composites contain short carbon filaments, ordinarily $5 \mathrm{~mm}$ long, as the short strands can be utilized as an admixture in cement (while constant strands can't be essentially added to the solid blend) and short filaments are more affordable than persistent filaments. Be that as it may, because of the frail bond between carbon fiber and the bond network, consistent filaments are significantly more compelling than short strands in fortifying cement.

The impact of carbon fiber expansion on the properties of solid increments with fiber volume portion, except if the fiber volume division is high to the point that the air void substance turns out to be too much high (The air void substance increments with fiber substance and air voids will in general negatively affect numerous properties, for example, the compressive quality).

The enhanced auxiliary properties rendered via carbon fiber expansion relate to the expanded malleable and adaptable qualities, the expanded tractable flexibility and flexural strength, the upgraded effect obstruction, the decreased drying shrinkage and the enhanced stop - defrost sturdiness.

The ductile and flexural qualities diminish with expanding example estimate, to such an extent that the size impact winds up bigger as the fiber length increments. The low drying shrinkage is profitable for extensive structures and for use in fix and in joining blocks in a block structure [5].

\section{Literature Survey}

This literature review will be limited to research of FRP material externally bonded to the tensile face of concrete beams. In particular, research studying the effect of externally applied FRP materials on the flexural performance of reinforced concrete beams will be reported.

Triantifillou and Plevris (1991) used strain compatibility and fracture mechanics to analyze reinforced concrete beams applied with externally bonded carbon fiber reinforced plastics (CFRP). The 
same assumptions as An et al. They were used with the inclusion of an rectangular compression stress distribution in the concrete at failure. [6].

Wasan I. Khalil and Akar Abdulrazaq: They mulled over those mechanical properties about high performance carbon fiber cement would contemplated. The test fill in includes, transforming secondary execution cement utilizing superplasticizer Furthermore condensed silica fume strengthened with diverse volume portions $(0 \%, 0.2 \%, 0.3 \%, 0.4 \%$ and $0.5 \%)$ about carbon fibers. Those impact about hacked carbon fibers on the mechanical properties (compressive strength, Part ductile Furthermore flexural strengths, Furthermore modulus of elasticity) for high performance cement might have been likewise examined. Generally, those Outcomes indicate that $\mathrm{s}$ were as from claiming carbon fibers enhances the mechanical properties of high performance cement. Likewise the Outcomes indicate that utilizing condensed silica fume concerning illustration proportion by weight about bond expands the compressive quality more than that concerning illustration supplanting replacement of weight cement. [7].

E. Mello, C. Ribellato and E. Mohamedelhassan: They investigated progress properties for concrete about cellulose, steel, carbon and PET fibers. Every fiber might have been included at four rates of the new concrete, which might have been moist-cured to 28-days et cetera tried for compressive, flexural Furthermore pliable qualities. Progressions clinched alongside quality What's more increments to expense were investigated. Effects demonstrated that expansion about cellulose acetic acid derivation created a diminish between 9 . $8 \%$ Also 16. 4\% On compressive quality. This extend might be worthy Likewise cellulose acetic acid derivation fibers could fundamentally expand those cement safety should fire, and solidifying Also defrosting cycles. Carbon fibers improve flexural Furthermore tensile qualities eventually up to $11 \%$ What's more $45 \%$, individually. Cement properties diminished then after addition fibers. Outcomes demonstrated that change in quality following expansion for steel and carbon fibers might defend the additional expense from claiming fibers[8].

S. M. Kinayekar , V. D. Gundakalle and Kishor Kulkarni: High Quality Cement (HSC)is thick, homogeneous and has the enhanced building properties and sturdiness as customary cement. Lately, HSC has increased wide application in the development business. High quality Cement is a solid having comparable fixings as customary concrete, for example, bond, fine total, coarse total and water. The glue of HSC requires high volume of concrete substance and less water to powder proportion. The soundness and stream capacity of HSC is finished by expanding the powder substance or work of powder admixtures. In any case, expanding the bond content reason surprising expense, higher warmth of hydration and higher drying shrinkage. This can be decreased by work powder admixture, for example, fly cinder and ground granulated impact heater slag and so forth. In the present examination, concrete substance for H.S.C blend is substitute with steady \% of fly slag (10\%) and carbon fiber are included vol. section ( 0 to $0.60 \%$ ), additionally the carbon Fiber Strengthened Polymer (CFRP) turf are put in different layer (single, twofold and triple layer) with adjust width of CFRP strip (0 to 80 $\mathrm{mm})$. The sustained solid properties of HSC were contemplated and the relapse examination was completed on the trial examination.

The investigation reasons that carbon filaments can be successfully utilized as a strengthening material in HSC[9].

Qais Hassan Fadel: He considered contain a test work to discover the advantage emerges from CFRP (Carbon Fiber reinf. Polymer) covers expansion to bond mix blend in diminishing the entire warm conductivity and the warmth exchange through development components, which increment warm protection and lessen utilization of power utilized for cooling gear.

Eight solid examples of rectangular cross areas were cast to inspect the warm conductivity, notwithstanding that a 12 standard solid 3D squares were set up to discover the compressive quality of cement. Carbon strands were cut and added with various adds up to get its impact on warmth exchange and warm conductivity for cement to contrast it and the compressive quality. Test results for warm conductivity for testing time of (390) minutes for every example demonstrated an expansion in warm protection for the reinforced cement, and this protection increments with expanding measure of CFRP included. The solid examples and shapes were separated into four gatherings of various measure of CFRP, which were $(0 \%, 0.45$ $\%, 1.1 \%, 1.6 \%)$ of concrete weight utilized in the blend. Notwithstanding that, the protection was expanded in the presence of CFRP, the compressive quality was diminished by (6.4-28.5) \%, while expanding CFRP sum, as for control concrete[10].

\section{Experimental Work}

\subsection{Cement}

In this research, Iraqi Ordinary Portland Cement (OPC Type I) manufactured in the north of Iraq with trade mark of (Al-Mass) was used . Its physical properties and chemical composition test results indicate that the adopted cement conforms to the Iraqi specifications (IQS No.5/ 1984)

\subsection{Sand}

Characteristic sand supplied from (Al-Mutasim state organization for development Contracts ) evaluating set zone 2 might have been utilized to those cement mixes in this worth of effort. Tests were conveyed out to figure out those gradation, fineness modulus also sulfate substance, know tests conforms on Iraqi standard ( IQS no. 45/1984 Zone 2).

\subsection{Gravel}

Round gravel with nominal max. size (5-14) mm might have been utilized similarly as a coarse aggregate on the whole mixes. It might have been brought starting with (Al-Nibaee) district. Tests were conveyed out to determine the gradation, spec. gravity, thickness what's more sulfate content, constantly on tests fit in with Iraqi standard ( IQS no. 45/1984).

\subsection{Water}

Those water utilized to both blending and curing might have been potable water from those water-supply system framework (tap water).

\subsection{High Performance Concrete Superplasticiser}

A high performance super plasticising commercially known as Flocrete PC200, was used in this research. It is a high strength concrete super plasticizer admixture dependent upon polycarboxylate whichever polymers for in length chains uncommonly intended will empower those water content of the cement with perform more successfully. Those measurement proposed eventually the maker is $(0.75-2.5)$ Liters $/ 100 \mathrm{~kg}$ from claiming powder materials in the blend. 


\subsection{Mineral Admixture (Silica Fume)}

Silica fume, as characterized in ACI 116R-2000, is "very fine non crystalline silica prepared over electric bend furnaces similarly as an by-result of the preparation of natural silicon alternately alloys holding silicon.". Those silica fume, condensed starting with the gasses escaping starting with those furnaces, need a helter skelter content about amorphophallus titanum silicon dioxide What's more comprises for extremely fine round particles normally averaging 0.1 should $0.2 \mu \mathrm{m}$ on breadth.

It is a profoundly pozzolanic material that is used to upgrade mechanical what's more sturdiness properties about cement. It might be included straightforwardly to cement as a distinct element alternately to an mix about Portland bond Furthermore silica fume (ACI 234R-06).

Silica fume need been distinguished similarly as a pozzolanic admixture that is compelling in upgrading the mechanical properties to an incredible degree. Eventually Tom's perusing utilizing silica seethe alongside superplasticizers, it is generally simpler with acquire compressive qualities of request of 100-150 MPa Previously, research center. Expansion of silica seethe to cement enhances those sturdiness about cement through diminishment in the permeability, refined pore structure, prompting an decrease in the dispersion for destructive ions what's more diminishes calcium hydroxide substance which brings about An higher safety should sulfate attack. The physical properties Furthermore concoction piece about SF utilized within this fill in conforms of the necessities from claiming ASTM C1240-05.

\subsection{Carbon fiber}

Carbon fiber is a synthetic fiber with Levy shape composed of carbon micro-crystals formed as a result of Tlyev consisting of acrylic processing distillates oil and coal resin at certain temperatures. Used in this research carbon-fiber cut short from producer company (Fosroc Jordan). And properties of fibers used are shown in the following table.

\subsection{Concrete Mix Design}

Laboratory experiments were divided into three mixes.The first mixture included (cement + water $+\mathrm{PC} 200+$ sand + gravel $)$, and the second mixture included (cement + water + PC200 + Silica fume + sand + gravel) and finally included (cement + water + carbon-fiber + Silica fume + sand + gravel). Those points of the mixes utilized for this ponder need aid provided for table 1 .

Table 1: Blend proportions utilized through this worth of effort

\begin{tabular}{|l|l|l|l|}
\hline Items & M1 & M2 & M3 \\
\hline Cement $\mathrm{Kg} / \mathrm{m} 3$ & 450 & 450 & 450 \\
\hline Silica fume $\mathrm{kg} / \mathrm{m} 3$ & - & 45 & 45 \\
\hline Water $\mathrm{L} / \mathrm{m} 3$ & 1380 & 1380 & 2200 \\
\hline Fine Aggregate Kg/m3 & 680 & 680 & 680 \\
\hline Coarse Aggregate Kg/m3 & 960 & 960 & 960 \\
\hline PC200 L/m3 & 2 & 2 & 2 \\
\hline FRC by vol \% & - & 0.5 & 0.75 \\
\hline
\end{tabular}

\section{Results and Discussion}

\subsection{Compressive Strength}

The compressive strength values at various ages for all types of HPC mixes cured in water are presented in Table 2 Also, the relationship between compressive strength and Fiber Carbon content.
Table 2: Compressive Strength Test Results for all HPC mixes

\begin{tabular}{|c|c|c|c|c|}
\hline $\begin{array}{c}\text { Mix } \\
\text { Symbol }\end{array}$ & FRC & 7 days & 28 days & 60 days \\
\hline M1 & 0 & 28 & 40 & 48.8 \\
\hline M2 & 0.5 & 32 & 45 & 54.9 \\
\hline M3 & 0.75 & 35 & 48.7 & 58 \\
\hline
\end{tabular}

It is seen from Table 2, that the all examples display an expansion in compressive quality with the advancement of age at constantly decreasing rate. This expansion in compressive quality is because of the coherence of bond hydration process which frames another hydration item inside the solid grid. Likewise, the present containing (10\%) SF has enhance the advancement of solidarity results. This enhancement is under the impact of silica smoke and fiber, which has concoction and physical impacts. . The concoction impact is basically due to the pozzolanic responses between the indistinct silica in SF and calcium hydroxide $(\mathrm{CH})$ created by the hydration of bond to frame calcium silicate hydrates $(\mathrm{C}-\mathrm{S}-\mathrm{H})$. The physical impact, which can likewise be considered as filler impact, is that SF particles increment the pressing of the strong materials by filling the spaces between the bond grains similarly as concrete fills the spaces between fine totals and fine totals fill the spaces between coarse totals in cement.

\subsection{Bulk Density}

The effect of curing ages on various concrete types; the results demonstrate that the density increases with time of curing for all types of concrete due to cement hydration and effect of silica fume and fiber.

It is found from the testing results as shown in Table 3 that the bulk density of plastic HPC considerably increase when the fiber carbon increase .

Table 3 : Bulk Density test results for all HPC mixes

\begin{tabular}{|l|l|l|l|l|}
\hline Mix & Fiber & \multicolumn{3}{|l|}{ Bulk Density $(\mathrm{Kg} / \mathrm{m} 3)$} \\
\cline { 3 - 5 } Symbol & Carbon & 7 days & 28 days & 60 days \\
\hline M 1 & 0 & 2330 & 2400 & 2485 \\
\hline M 2 & 0.5 & 2400 & 2450 & 2495 \\
\hline M 3 & 0.75 & 2332 & 2480 & 2500 \\
\hline
\end{tabular}

\subsection{Flexural Strength (Modulus of Rupture)}

The results exhibited a continuous increase in flexural strength for all type of HPC with increasing curing age and with contain fiber. This is attributed to both physical actions and chemical effect (pozzolanic action) of silica fume and fiber which improving properties of concrete by increased the dense hydrated calcium silicate in concrete structure, as mentioned previously .

The effect of fiber on flexural tensile strength is shown in Table 4 , which indicates that there is an increase in the flexural tensile strength for all plastic HPC ( M2, and M3), draw an with ref. HPC (M1).

Table 4 : Flexural tensile strength test results for all HPC mixes

\begin{tabular}{|c|c|c|c|}
\hline $\begin{array}{c}\text { Mix } \\
\text { Symbol }\end{array}$ & 7 days & 28 days & 60 days \\
\hline M1 & 3.1 & 4.8 & 5.0 \\
\hline M2 & 4.0 & 5.9 & 6.1 \\
\hline M3 & 4.8 & 6.1 & 6.4 \\
\hline
\end{tabular}




\section{References}

[1] Prof. Zongjin Li. Department of CivilEngineering Teaching Assistants: Zhang Jie, Qiao Fei,. Li Xiangyu, Qin Lei. " Civl 111 Construction Materials".

[2] S. Releases., "Carbon Fiber Industry Statistics", Composites News, No. 1, (1998).

[3] S. Plenary Describes .,"Carbon Fiber Capacity, Trends", Composites News, No. 6,( 1998).

[4] Raouf, Zain..," Dynamic mech. Prop. of Fibre-Reinf. Cem. Composites", Ph. D. Thesis, Univ. of Manchester, May, P. 35,( 1975).

[5] D.D.L. Chung., "Cem. Reinf. with short carbon fibres: a multifunctional material" , Composites: Part b 31 511-526 (2000) .

[6] TC Triantafillou, N Deskovic " mechanics of short-term behavior "Journal of Engineering Mechanics 117 (7), 1652-1672.

[7] Wasan I.K \& Akar A., " Mech. Properties of HPF Concrete",Eng \& Tech.Journal,Vol.29,No.5, (2011).

[8] E. Mello, C. Ribellato, E. Mohamedelhassan," Improving Concrete Properties with Fibers Addition", International Journal of Civil, Architectural, Structural and Construction Engineering Vol:8 No:3, (2014).

[9] S. M. Kinayekar \& et al, " The Effect of Addition of Carbon Fibers on Mech.Properties of High Strength Conc.", International Journal of Innovative Research in Science, Engineering and Technology, Vol. 3, Issue 1, January (2014).

[10] Q.Hassan," Effect Of Carbon Fibers Amount On Concrete Thermal Conductivity And Compressive Strength",(2011) 